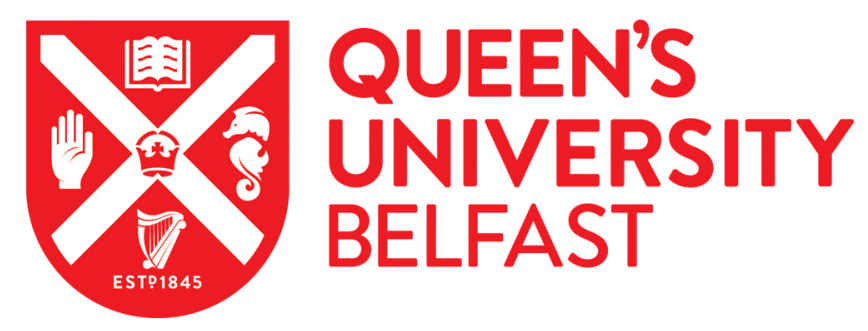

\title{
Micromechanical analysis of interlaminar crack propagation between angled plies in mode I tests
}

\author{
Varandas, L. F., Arteiro, A., Catalanotti, G., \& Falzon, B. G. (2019). Micromechanical analysis of interlaminar \\ crack propagation between angled plies in mode I tests. Composite Structures. \\ https://doi.org/10.1016/j.compstruct.2019.04.050
}

\section{Published in:}

Composite Structures

\section{Document Version:}

Peer reviewed version

Queen's University Belfast - Research Portal:

Link to publication record in Queen's University Belfast Research Portal

\section{Publisher rights}

This manuscript version is made available under the CC-BY-NC-ND 4.0 license http://creativecommons.org/licenses/by-nc-nd/4.0/,which permits distribution and reproduction for non-commercial purposes, provided the author and source are cited.

\section{General rights}

Copyright for the publications made accessible via the Queen's University Belfast Research Portal is retained by the author(s) and / or other copyright owners and it is a condition of accessing these publications that users recognise and abide by the legal requirements associated with these rights.

Take down policy

The Research Portal is Queen's institutional repository that provides access to Queen's research output. Every effort has been made to ensure that content in the Research Portal does not infringe any person's rights, or applicable UK laws. If you discover content in the Research Portal that you believe breaches copyright or violates any law, please contact openaccess@qub.ac.uk. 


\section{Accepted Manuscript}

Micromechanical analysis of interlaminar crack propagation between angled plies in mode I tests

L.F. Varandas, A. Arteiro, G. Catalanotti, B.G. Falzon

PII: S0263-8223(18)34360-5

DOI: https://doi.org/10.1016/j.compstruct.2019.04.050

Reference: COST 10878

To appear in:

Composite Structures

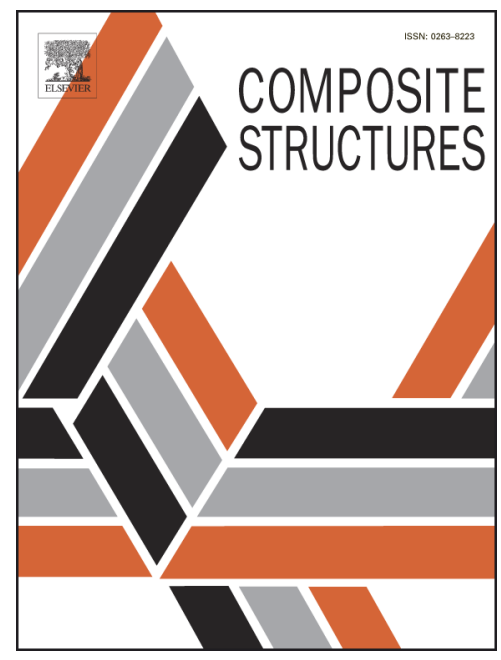

Please cite this article as: Varandas, L.F., Arteiro, A., Catalanotti, G., Falzon, B.G., Micromechanical analysis of interlaminar crack propagation between angled plies in mode I tests, Composite Structures (2019), doi: https:// doi.org/10.1016/j.compstruct.2019.04.050

This is a PDF file of an unedited manuscript that has been accepted for publication. As a service to our customers we are providing this early version of the manuscript. The manuscript will undergo copyediting, typesetting, and review of the resulting proof before it is published in its final form. Please note that during the production process errors may be discovered which could affect the content, and all legal disclaimers that apply to the journal pertain. 


\title{
Micromechanical analysis of interlaminar crack propagation between angled plies in mode I tests
}

\author{
L.F. Varandas ${ }^{\mathrm{a}}$, A. Arteiro ${ }^{\mathrm{b}}$, G. Catalanotti ${ }^{\mathrm{a}, *}$, B.G. Falzon ${ }^{\mathrm{a}}$ \\ ${ }^{a}$ Advanced Composites Research Group (ACRG), School of Mechanical and Aerospace Engineering, Queen's \\ University Belfast, Belfast BT9 5AH, UK \\ ${ }^{b}$ DEMec, Faculdade de Engenharia, Universidade do Porto, Rua Dr. Roberto Frias, 4200-465, Porto, Portugal
}

\begin{abstract}
This paper presents a micromechanical finite element model to study interlaminar damage propagation and relocation, known as delamination migration, between angled plies, consisting of a double-ply $\theta / 0^{\circ}$ Unit Cell (UC) in-between homogenised unidirectional $0^{\circ}$ plies. Random fibre distributions and appropriate constitutive models are used to model the different dissipative phenomena that occur at crack onset and propagation. Varying the upper ply fibres orientation, $\theta$, and ply thickness, it is possible to assess their influence on the damage migration mechanism. Different features associated with delamination migration are analysed, such as the distribution of interlaminar shear stresses at the crack tip and the kink angles. When comparing the results of the micromechanical model with previously conducted experimental observations, similar trends are obtained. It is concluded that the computational framework is able to simulate mode I interlaminar damage propagation and delamination migration in multidirectional laminates, providing a sound tool to better understand the conditions behind interlaminar crack migration.
\end{abstract}

Keywords: Delamination migration, Polymer-matrix composites (PMCs), Matrix cracking, Computational mechanics

\section{Introduction}

Delamination may result from manufacturing defects (such as voids, pores, or inclusions between layers), from impact or from geometric discontinuities, which can induce early laminate failure and cause a significant reduction in the load carrying capacity of a structure [1]. In particular, the resistance to delamination in multidirectional laminates needs to be well understood, since interlaminar damage usually occurs along the interface of laminae with different fibre orientations 2. Under certain conditions, delamination migration may also occur leading to its relocation from an interlaminar region to another through an intralaminar matrix crack. This mainly depends upon the direction of

\footnotetext{
* Corresponding author

Email address: G.Catalanotti@qub.ac.uk (G. Catalanotti)
} 
the interlaminar shear stresses and orientation of the fibrous reinforcements [3]. Figure 1 shows a crack migration. Canturri et al. 9] investigated the influence of ply interface on the delamination propagation process, concluding that delaminations propagate preferentially in the direction of one ply at the delaminating interface. They further proposed a methodology for modelling delamination directionality. Ratcliffe et al. [10, 11] investigated and explained in detail the mechanism by which neighbouring interface for a $0^{\circ} / 90^{\circ}$ laminate. In their experiments, using Single Cantilever Beam (SCB) specimens, the delamination propagated along the lower $0^{\circ} / 90^{\circ}$ interface until a single matrix crack migrated to the next $90^{\circ}$ interface. The authors studied also the effect of the load offset with respect to the crack tip, and have observed that this influences the initial interlaminar shear stress an experimental study on delamination migration in angle-ply laminates, namely for specimens with $\theta=60^{\circ}$ and $75^{\circ}$. The experimental setup used was the same proposed by Ratcliffe et al. [10, 11. For 
the case of angle-ply laminates, it was found that the delamination migration process can be more complex, where many kinking events (corresponding to the relocation of the delamination into the $\theta$ ply) were observed before the crack completely migrated into the neighbouring ply. They confirmed that the migration process is inherent to delamination between plies of different orientations and it may thus be necessary to account for it in the development of mesomechanical intralaminar damage models. Gong et al. [13] investigated the delamination migration process under mode I quasi-static and fatigue loadings for specimens with a $+\theta /-\theta$ centreline interface, with $\theta=60^{\circ}$ and $\theta=75^{\circ}$. All migration in angle-ply laminates, using the Finite Element Method (FEM) [15, the XFEM-CE method (a method combining the extended finite element method (XFEM) with cohesive elements [16]), the Floating Node Method (FNM) combined with the Virtual Crack Closure Technique (VCCT) [17, 18], and the Extended Cohesive Damage Model (ECDM) [19]. In particular, Chen et al. [20, by making migration across the width of the laminate, as observed in the literature [12], as well as the effect of load offset on the locations where migration occurs.

Despite the previously enumerated experimental and numerical studies, the mechanisms that lead to interlaminar crack migration have not been fully comprehended. In the present work, computaphenomena. Computational micromechanics has emerged as a powerful tool to study the mechanical response of laminated composites [21, 22, 23, 24, 25, 26, 27, and it allows a more flexible and in-depth assessment of several factors, such as the stacking sequence, the damage mechanisms associated with interlaminar crack propagation (branching, bridging, and migration), and the imposed stress states, and their effect on the fracture properties [25]. In the present paper, using appropriate constitutive models for the composite constituents and the fibre-matrix interface, combined with an efficient modelling strategy, interlaminar damage relocation in angle-ply sublaminates is investigated in detail, including the effect of the stacking sequence and micromechanical damage mechanisms involved.

To the authors' knowledge, this is the first time computational micromechanics is applied in a systematic way to understand interlaminar crack propagation and relocation in multidirectional composite laminates. Previous attempts to model delamination migration in multidirectional laminates were restricted to mesoscale models, using homogenised composite plies [15, 16, 17, 18, 19, 20, and 
thus did not provide enough detail to capture microscale features such as the full migration history, including inititation and intralaminar propagation, the role of the different constituents (particularly the role of fibre-matrix interface), or the effect of ply thickness and orientation. Other studies have addressed interlaminar damage evolution of multidirectional reinforcements using mesoscale modelling approaches, but have not specifically addressed the delamination relocation issue [28, 29].

The structure of the paper is organised as follows. The constitutive models for each part of the computational framework are described in Section 2, followed by the micromechanical FE modelling strategy in Section 3 . The numerical results are presented in Section 4 and, finally, the conclusions are drawn in Section 5 .

\section{Constitutive modelling}

The FE model consists of a micromechanical Unit Cell (UC) that is composed of two plies with a $\theta / 0^{\circ}$ orientation, adjacent homogenised unidirectional $0^{\circ}$ layers and their interfaces (see Figure 2 ). In order to guarantee that the model is sufficiently large to accurately model the kinematics of a delamination test, homogenised plies were also attached to the UC through Tie Constraints. Figure 3 shows two different schematic views of the FE models.

[Figure 2 about here.]

The reinforcing fibres are disposed randomly in both $0^{\circ}$ and $\theta$ plies, by making use of the algorithm proposed in [25]. The fibres are embedded in an epoxy matrix, with interfaces between them. The homogenised laminae are used to simulate the mesoscale elastic behaviour of the composite represented by the micromechanical $\mathrm{UC}$, to constrain the micromechanical discretisation, and to ensure that the model is sufficiently long to accurately model delamination migration (see Figure 3b). The constitutive models for each of the materials are described in the coming sub-sections.

[Figure 3 about here.]

\subsection{Fibrous reinforcements}

Since it is assumed that damage will develop only in the matrix and at the fibre-matrix interface, a linear-elastic, transversely isotropic constitutive model is used to model the fibres. The geometry and material properties of the IM7 carbon fibres are reported in Table 1. 


\subsection{Epoxy matrix}

The isotropic damage model for the matrix proposed by Melro et al. [30] is used here, and the reader is referred to [21, 30]. For the sake of completeness the most fundamental details are reported below.

Following Melro et al. [30] the stress tensor, $\boldsymbol{\sigma}$, reads:

$$
\boldsymbol{\sigma}=\boldsymbol{D}^{e}: \varepsilon^{e}
$$

where $\varepsilon^{e}$ is the elastic strain tensor, and $\boldsymbol{D}^{e}$ is the elasticity fourth-order tensor. Rearranging Eq. (1) the hydrostatic pressure, $p$, can be expressed as a function of the elastic volumetric strain, $\varepsilon_{v}^{e}$, and the matrix bulk modulus, $K_{m}$ :

$$
p=K_{m} \varepsilon_{v}^{e}
$$

while the deviatoric stress tensor, $\boldsymbol{s}$, reads:

$$
s=2 G_{m} \varepsilon_{d}^{e}
$$

where $G_{m}$ is the matrix shear modulus, and $\varepsilon_{d}^{e}$ the deviatoric strain tensor. Following [31] the paraboloidal yield criterion is defined as:

$$
f\left(\boldsymbol{\sigma}, \sigma_{Y_{c}}, \sigma_{Y_{t}}\right)=6 J_{2}+2\left(\sigma_{Y_{c}}-\sigma_{Y_{t}}\right) I_{1}-2 \sigma_{Y_{c}} \sigma_{Y_{t}}
$$

where $\sigma_{Y_{t}}$ and $\sigma_{Y_{c}}$ are the absolute values of the tensile and compressive yield strengths, $I_{1}=\operatorname{tr}(\boldsymbol{\sigma})$ is the first invariant of the stress tensor and $J_{2}=\frac{1}{2} s: s$ is the second deviatoric stress tensor $(s)$ invariant.

To correctly define the volumetric deformation of the matrix, when a hydrostatic pressure is applied, a non-associative flow rule [30] was employed. The plastic potential reads:

$$
\mathrm{g}=\sigma_{v m}^{2}+\alpha p^{2}
$$

where $\sigma_{v m}=\sqrt{3 J_{2}}$ is the Von Mises stress and $\alpha$ is a material parameter defined as [30]:

$$
\alpha=\frac{9}{2} \frac{1-2 \nu_{p}}{1+\nu_{p}}
$$

with $\nu_{p}$ being the plastic Poisson's ratio.

Using the plastic potential of Eq. [5] the increment of plastic deformation reads:

$$
\Delta \varepsilon^{p}=\Delta \lambda \frac{\partial \mathrm{g}}{\partial \sigma}
$$


where $\Delta \lambda$ is the plastic multiplier.

The yield surface (Eq. (4)) depends only on the tensile and compressive yield strengths that are both affected by hardening. This is considered depending on the equivalent plastic strain:

$$
\sigma_{Y_{c}}=\sigma_{Y_{c}}\left(\varepsilon_{e}^{p}\right), \quad \sigma_{Y_{t}}=\sigma_{Y_{t}}\left(\varepsilon_{e}^{p}\right)
$$

Figure 4 shows the hardening curves used in the plasticity model in tension and in compression, respectively.

The equivalent plastic strain $\varepsilon_{e}^{p}$ is defined as:

$$
\varepsilon_{e}^{p}=\sqrt{\frac{1}{1+2 \nu_{p}^{2}} \varepsilon^{p}: \varepsilon^{p}}
$$

Following [30, the complementary free energy density is defined as:

$$
\begin{aligned}
\mathscr{G}_{m}= & \frac{\sigma_{11}^{2}+\sigma_{22}^{2}+\sigma_{33}^{2}}{2 E_{m}\left(1-d_{m}\right)}-\frac{\nu_{m}}{E_{m}}\left(\sigma_{11} \sigma_{22}+\sigma_{22} \sigma_{33}+\sigma_{33} \sigma_{11}\right)+ \\
& +\frac{1+\nu_{m}}{E_{m}\left(1-d_{m}\right)}\left(\sigma_{12}^{2}+\sigma_{13}^{2}+\sigma_{23}^{2}\right)+\mathscr{G}_{m}^{p}
\end{aligned}
$$

where, $E_{m}, \nu_{m}$ and $d_{m}$ are the Young's modulus, the Poisson's ratio and the damage variable for the matrix, respectively.

$\mathscr{G}_{m}^{p}$ represents the contribution of plastic flow to the stored energy. The irreversibility of the damage process is ensured if:

$$
\dot{\mathscr{G}}_{m}-\dot{\boldsymbol{\sigma}}: \varepsilon \geqslant 0
$$

A positive dissipation of mechanical energy is ensured if the strain tensor equals the derivative of the complementary free energy density with respect to the stress tensor:

$$
\boldsymbol{\varepsilon}=\frac{\partial \mathscr{G}_{m}}{\partial \boldsymbol{\sigma}}=\frac{\boldsymbol{\sigma}}{2 G_{m}\left(1-d_{m}\right)}-\frac{\nu_{m} d_{m}}{E_{m}\left(1-d_{m}\right)} \boldsymbol{I} \cdot \boldsymbol{I}: \boldsymbol{\sigma}-\frac{\nu_{m}}{E_{m}} I_{1} \boldsymbol{I}
$$

Finally, the damage onset is defined as:

$$
F_{m}^{d}=\phi_{m}^{d}-r_{m}
$$

where $r_{m}$ is an internal variable related with $d_{m}$, and $\phi_{m}^{d}$ represents the loading function:

$$
\phi_{m}^{d}=\frac{3 \tilde{J}_{2}}{X_{m}^{c} X_{m}^{t}}+\frac{\tilde{I}_{1}\left(X_{m}^{c}-X_{m}^{t}\right)}{X_{m}^{c} X_{m}^{t}}
$$


where $X_{m}^{c}$ and $X_{m}^{t}$ represent the compressive and tensile strengths of the material, while invariants $\tilde{J}_{2}$ and $\tilde{I}_{1}$ are determined using the effective stress tensor.

Bažant and Oh's crack band model 32 is used together with an appropriate damage evolution law, in order to eliminate mesh size dependency. The dissipated energy reads:

$$
\Psi_{m}=\int_{0}^{\infty} Y_{m} \dot{d}_{m} \mathrm{~d} t=\int_{1}^{\infty} \frac{\partial \mathscr{G}_{m}}{\partial d_{m}} \frac{\partial d_{m}}{\partial r_{m}} \mathrm{~d} r_{m}=\frac{\mathcal{G}_{I c}^{m}}{l^{e}}
$$

\subsection{Fibre-matrix interface}

The fibre-matrix interface is modelled using the cohesive surfaces of the FE commercial software Abaqus ${ }^{\circledR}$ 33. Before damage initiation, a linear traction separation behaviour is assumed. Damage initiation is predicted using a stress-based quadratic failure criterion [34. Damage evolution is based on the energy dissipated as a result of the damage process, adopting an exponential softening response under mode I, mode II or mixed-mode, according to the Benzeggagh-Kenane (BK) law [35]. The material properties for the interface are presented in Table 3. Acknowledging the challenge in determining interfacial strength and toughness, the parameters used in this work are based on available experimental data 36, 37, 38, and on previous micromechanical simulations [21, 24, 39, 40].

60

\subsection{Homogenised plies}

The homogenised plies are modelled assuming a linear-elastic transversely isotropic material behaviour. Since they are introduced in the micromechanical model to reduce computational cost, no nonlinear or fracture behaviour is considered. The elastic properties of the plies can be determined

[Table 3 about here.] with micromechanical analyses using the concept of Representative Volume Element (RVE) and Periodic Boundary Conditions (PBCs), making use of the procedure outlined by Catalanotti 41 for the 
generation of a random distribution of fibres, combined with the already reported mechanical properties of the constituents. A value of a fibre volume fraction of $\omega_{f}^{\text {ply }}=60 \%$ is used throughout the simulations.

Figure 5, shows one of the generated RVEs used for the determination of the elastic properties of the outer laminae, outlining its geometrical periodicity.

[Figure 5 about here.]

Assuming a transverse isotropic material, the six independent elastic properties of the homogenised plies can be determined using the following equations:

$$
\begin{aligned}
E_{11} & =C_{1111}-\frac{2 C_{1122}^{2}}{C_{2222}+C_{2233}} \\
E_{22} & =\left(C_{2222}-C_{2233}\right) \frac{C_{1111}\left(C_{2222}+C_{2233}\right)-2 C_{1122}^{2}}{C_{1111} C_{2222}-C_{1122}^{2}} \\
\nu_{12} & =\frac{C_{1122}}{C_{2222}+C_{2233}} \\
\nu_{23} & =\frac{C_{1111} C_{2233}-C_{1122}^{2}}{C_{1111} C_{2222}-C_{1122}^{2}} \\
G_{12} & =C_{4444} \\
G_{23} & =C_{6666}=\frac{1}{2}\left(C_{2222}-C_{2233}\right)
\end{aligned}
$$

where $C_{i j k l}$ are the components of the stiffness tensor in Voigt notation.

The volume average of the strain in the RVE equals the applied far-field strain, $\varepsilon_{i j}^{0}$ :

$$
\bar{\varepsilon}_{i j}=\frac{1}{V} \int_{V} \varepsilon_{i j} \mathrm{~d} V=\varepsilon_{i j}^{0}
$$

In order to obtain the stiffness matrix, and determine the six independent elastic properties of the material using Eqs. 17a)-17f], the RVEs are submitted to six independent unit load cases (three normal and three shear loads). The applied strain is a unit value for one of the far-field strain components and zero for the remaining strain components. This way, each component of the stiffness tensor will be equal to the volume average of the stress field:

$$
C_{i j k l}=\bar{\sigma}_{i j}=\frac{1}{V} \int_{V} \sigma_{i j} \mathrm{~d} V, \quad \text { with } \varepsilon_{k l}^{0}=1
$$

According to Melro et al. 42, the RVE transverse and longitudinal dimensions influence the predictions of the elastic response. In order to accurately capture the ply level elastic mechanical properties, square RVEs with in-plane dimensions of $30 r$ and with a longitudinal dimension of $4 r$ are used. Fibres and matrix are modelled using C3D8, three-dimensional, fully integrated linear hexahedral elements, 
with an average size of $0.7 \mu \mathrm{m}$, with the corresponding material properties previously reported in sections 2.1 and 2.2 . Table 4 summarises the results of the mean, minimum and maximum values of ten different generated RVEs with the same fibre volume fraction $\left(\omega_{f}^{\text {ply }}=60 \%\right)$, same size, but with different fibre distributions. The value of the homogenised density was obtained following Chamis' crack propagation between angled plies in mode I tests. The application of the displacement is in a place that promotes delamination kinking and subsequent migration without delamination growth prior to migration. Hence $\mathrm{S}=0$ is assumed throughout the paper, corresponding to the conventional DCB specimen used to evaluate mode I interlaminar fracture toughness, but with a micro-discretisation 215

[Table 4 about here.]

\subsection{Ply interfaces}

The interfaces between the UC and the unidirectional $0^{\circ}$ homogenised outer layers are modelled using cohesive surfaces in Abaqus ${ }^{\circledR}$ 33. The formulation is the same used for the fibre-matrix interface described in sub-section 2.3 The relevant material properties are given in Table 5 . Because they are well documented, the interlaminar properties of the IM7/8552 carbon-epoxy composite laminate [43] are used.

[Table 5 about here.]

\section{Finite element modelling}

\subsection{Finite element discretisation}

Ratcliffe et al. [10, 11] developed an experimental setup to evaluate delamination migration. Figure 6 shows a schematic representation of the test.

[Figure 6 about here.]

According to experimental studies using SCB specimens [11, 12, delamination growth takes place prior to migration for cases where the load offset with respect to the crack tip location is higher than 0.5 , (i.e. $\mathrm{S} / a_{0}>0.5$ ) with a distance varying from $13 \mathrm{~mm}$ to $16 \mathrm{~mm}$. Cases where $\mathrm{S} / a_{0} \leqslant 0.5$ exhibited delamination migration immediately from the Polytetrafluoroethylene (PTFE) film insert, since the shear stresses acting in the vicinity of the insert front tend to favour kinking of the delamination into the upper $\theta$ ply [10]. Due to the computational cost of the proposed micromechanical models, a comparison study of the load offset is not performed. Instead, it is chosen to study only interlaminar of a UC long enough to fully capture the migration to the next interface. 
Figure $3 \mathrm{a}$ shows a schematic view of the double-ply $\theta / 0^{\circ} \mathrm{UC}$ with the top homogenised outer plies, where $t$ is the thickness of each individual outer lamina, equal to the thickness of a single ply of the $\mathrm{UC}(h), L_{\mathrm{UC}}$ is the total length of the $\mathrm{UC}$, which is kept constant and equal to $0.7 \mathrm{~mm}$ throughout the analyses, and $H$ is the width of the UC. This width was chosen to be constant and equal to 0.105 $\mathrm{mm}$ for all the UCs investigated. It is understood that the ratio $H / h$ has to be long enough in order to ensure that the numerical predictions are not influenced by this parameter. This can be easily done for very thin UCs. However, for the thicker UCs, this would result in a prohibitive computational effort. Therefore, the value chosen for $H$ yields a good compromise between the computational cost and the ability of the model to capture all features associated with delamination propagation and migration. A resin rich area was created by positioning the plies at a distance $w=4 \mu \mathrm{m}$ in order to appropriately evaluate the damage process. The total thickness of the $\mathrm{UC}$ is then $W=2 h+w$. Since the objective is not the evaluation of the mode I interlaminar fracture toughness, involving the complete development of the Fracture Process Zone (FPZ), the effect of the length of the UC is not studied. However, in order to guarantee that the model is able to represent the mode I experimental test setup, the total length of the model, $L_{\mathrm{tot}}=L_{\mathrm{UC}}+L_{\mathrm{hom}}+a_{0}$ is set to $22.99 \mathrm{~mm}$, where $L_{\mathrm{hom}}=13.65 \mathrm{~mm}$ and $a_{0}=8.64 \mathrm{~mm}$. The aforementioned dimensions were chosen since the same $\left(a_{0}+a_{0}^{\mathrm{UC}}\right) / L_{\text {tot }}$ ratio is used in the DCB test standard [44]. Figure 3b shows a schematic view of the entire model. A geometric pre-crack was inserted in the UC by removing elements along the centreline of the interlaminar resin-rich area (see Figure 8) to force delamination growth from that location, with a length $a_{0}^{\mathrm{UC}}=0.2 \mathrm{~mm}$. This pre-crack length was chosen to ensure that damage onset and propagation is not influenced by other features of the model, such as the Tie Constraints between the UC and the homogenised plies, and that damage will occur within the UC and its propagation will not depend on the boundary conditions.

To represent the microscale geometry, C3D4, three-dimensional tetrahedral continuum solid elements, with an average size of $1.5 \mu \mathrm{m}$ are used to discretise the fibres and matrix. The homogenised outer unidirectional $0^{\circ}$ plies are modelled by means of C3D8R, three-dimensional, reduced integration hexahedral elements, also with an average size of $1.5 \mu \mathrm{m}$. The homogenised plies that are attached to the UC are modelled in the same manner (type of elements and average seed size) as the other homogenised plies, but with a biased local seed size along their length from $0.25 \mathrm{~mm}$ to $2 \mathrm{~mm}$. Thus, the smaller $(h=35 \mu \mathrm{m})$ and the larger models $(h=125 \mu \mathrm{m})$ have approximately 3.5 and 11.5 million 245 elements, respectively.

\subsection{Loading and boundary conditions}

For mode I interlaminar crack propagation evaluation, a vertical ( $z$-direction) tensile velocity is applied to the upper left edge of the unidirectional $0^{\circ}$ homogenised part, corresponding at the end of the step to a displacement with a magnitude of approximately the total UC thickness. The axial 

unidirectional $0^{\circ}$ homogenised part is fixed in the longitudinal and out-of-plane directions, and finally one of the side faces of the model has the transverse ( $y$-direction) displacements blocked. Figure $3 \mathrm{~b}$ shows the boundary conditions applied to the model.

\section{Numerical predictions}

The numerical simulations were conducted using the FE solver Abaqus ${ }^{\circledR} /$ Explicit 33]. The purpose of these simulations is to study the delamination migration phenomena, involving the fracture of the epoxy matrix and fibre-matrix debonding. In order to avoid numerical errors due to excessive element distortion, damaged elements $\left(d_{m}>0.99\right)$ have been removed throughout the simulations. The FE models run in one node (20 CPUs of Intel ${ }^{\circledR}$ Hashwell $\left.{ }^{\circledR}\right)$ with 512GB of RAM. The smaller $(h=35 \mu \mathrm{m})$ and the larger models $(h=125 \mu \mathrm{m})$ take, respectively, approximately five and twenty days to run in such conditions.

\subsection{Effect of ply thickness}

Preliminary studies were conducted to assess the effect of ply thickness on delamination migration. Figure 7 shows the contour plots of the matrix damage variable for four different $75^{\circ} / 0^{\circ} \mathrm{UCs}$ with ply thicknesses $h=35 \mu \mathrm{m}, h=65 \mu \mathrm{m}, h=95 \mu \mathrm{m}$ and $h=125 \mu \mathrm{m}$ (the outer homogenised plies thickness, $t$, increases proportionally) at maximum applied displacement.

[Figure 7 about here.]

It can be seen that independently of the thickness of the UCs, the crack that developed at the pre-crack tip migrated as an intralaminar through-thickness matrix crack until it reached the next interlaminar region. An interesting remark is the fact that for some ply thicknesses (Figures $7 \mathrm{~b}$ and $7 \mathrm{c}$, damage is not initially developed at the pre-crack tip due to the proximity of the fibres to the initial crack, promoting matrix damage growth towards the closest (weak) fibre-matrix interface.

[Figure 8 about here.]

The kink angle (or migration angle), $\Omega_{\mathrm{o}}$, is defined as the angle between the horizontal line ( $x$ 275 direction) in the current defect plane and the commencing linear section of the migrated crack (see Figure 1) [13, 14]. The kink angles decrease with increasing ply thickness. The values reported in the literature obtained for the migration angles, taken from the front sides of the specimens via microscopic observations [14] ranged from $\Omega_{0} \in\left[35^{\circ}, 60^{\circ}\right]$. The numerical predictions of the kink angles presented in the previous figure are approximately $\Omega_{0} \approx 62^{\circ}, \Omega_{0} \approx 57^{\circ}, \Omega_{0} \approx 35^{\circ}$ and $\Omega_{0} \approx 30^{\circ}$, with increasing ply thickness. It is postulated that migration angles are governed by the magnitude of the 
interlaminar shear stress. With these micromechanical models it is simple to obtain the distribution of the interlaminar shear stresses across the width of the UCs. Figure 9 shows the numerical predictions of the magnitude of the interlaminar shear stress distributions for the four $75^{\circ} / 0^{\circ} \mathrm{UCs}$ at onset of crack propagation, corresponding to the moment when the damage variable of the elements surrounding the crack tip is higher than zero, (i.e. when the failure criterion has been satisfied and softening begins).

[Figure 9 about here.]

As expected, all UCs present a positive interlaminar shear stress distribution causing the crack to migrate. It can also be seen that the magnitude of the shear stress decreases with increasing ply thickness, reason why the thicker laminates present smaller migration angles. This observation is supported by the direction of the maximum principal stress, which becomes more vertical as the shear stress magnitude drops (see Figure 10 ).

[Figure 10 about here.]

Another simulation was conducted to further assess the effect of the magnitude of the interlaminar shear stresses on the kink angles, by increasing the homogenised outer plies thickness, $t$, to $125 \mu \mathrm{m}$, with $h=35 \mu \mathrm{m}$. Figure 11 shows the contour plots of the matrix damage variable (Figure 11a) and a quantitative comparison between the interlaminar shear stress distributions along the width of the UCs at the pre-crack tip at onset of crack propagation (Figure 11b for UCs with $h=35 \mu \mathrm{m}$ and $t=35 \mu \mathrm{m}$ and $t=125 \mu \mathrm{m}$, respectively.

[Figure 11 about here.]

It can be seen that for the case of $h=35 \mu \mathrm{m}$ and $t=125 \mu \mathrm{m}$, the kink angle decreased $\left(\Omega_{0} \approx 40^{\circ}\right)$, caused by a decrease of the magnitude of the distribution of the interlaminar shear stresses.

Based on these results, and due to the high computational cost of these finite element models, in the following numerical analyses, a constant thickness equal to $h=35 \mu \mathrm{m}$ was selected for each ply of the UCs.

\subsection{Effect of off-axis angle}

Here, a more detailed evaluation of the delamination migration mechanism is given through the analysis of seven different stacking sequences that are generated for increments of $15^{\circ}$ of the upper ply reinforcement orientation in the range $0^{\circ} \leq \theta \leq 90^{\circ}$, for a constant ply thickness. Figure 12 shows the contour plots of the matrix damage variable at the maximum applied displacement on the $0^{\circ} / 0^{\circ}, 45^{\circ} / 0^{\circ}$ and $90^{\circ} / 0^{\circ} \mathrm{UCs}$. As expected, in the $0^{\circ} / 0^{\circ} \mathrm{UC}$ (Figure 12a), a crack develops at the crack tip and propagates stably in the interlaminar region. However, in both $45^{\circ} / 0^{\circ}$ and $90^{\circ} / 0^{\circ} \mathrm{UCs}$ 
(Figures 12b - 12c), damage does not propagate along the interlaminar region. Instead, the crack tends to grow towards the upper homogenised ply, directly from the location of the initial crack tip, as reported in [13, through an intralaminar matrix crack.

For the sake of brevity, only the contour plots of the matrix damage variable at the maximum applied displacement of the remaining upper ply fibre orientations are shown (Figure 13). It can be seen that migration occurred for all the stacking sequences except for the cases of the $0^{\circ} / 0^{\circ}$ and $15^{\circ} / 0^{\circ}$ UCs. Part of the crack developed in the $30^{\circ} / 0^{\circ}$ UC propagated to a fibre-matrix interface in the $0^{\circ}$ ply, however, the main crack managed to propagate all the way through the $30^{\circ} \mathrm{ply}$, reaching the next interlaminar region. It is also noted that some smeared damage can be observed in the matrix of the $0^{\circ}$ plies (e.g. Figure $(7 \mathrm{c}$ and $13 \mathrm{~b})$ ), attributed to the weak fibre-matrix interface and random fibre/matrix discretisation of the UCs, with a negligible effect on the results though.

[Figure 13 about here.]

From Figures 12 and 13 , it can be seen that, in some cases, crack branching occurs, as reported experimentally in 7]. At the macroscale, delamination migration is characterised by an interlaminar crack that relocates to another interface through the formation of a through-thickness intralaminar crack. However, at the microscale, delamination migration becomes a more complex mechanism that involves different dissipative phenomena, including local plastic deformation of the matrix, fibre-matrix debonding and matrix cracking and branching. At the laminate level, most of these mechanisms cannot be visually distinguished and therefore their interaction is neglected. Numerical predictions are presented in Figure 14 where the normalised load-displacement curves are reported, with $F_{z}$ as the reaction force in the $z$-direction, and $F_{0^{\circ}}^{c} / 0^{\circ}$ as the maximum value of the reaction force of the $0^{\circ} / 0^{\circ}$ UC. It is observed that the $0^{\circ} / 0^{\circ}$ and $15^{\circ} / 0^{\circ} \mathrm{UCs}$ exhibit a clear peak load. The crack did not migrate, and instead propagated along the interlaminar region, leading to a stable post-peak response. However, all the remaining stacking sequences presented an unstable post-peak response, involving several load oscilations, which may be attributed to damage being propagated through fibre-matrix interfaces. The $90^{\circ} / 0^{\circ} \mathrm{UC}$ mechanical response is rather poor, due to the lower resistance to intralaminar fracture of the $90^{\circ}$ off-axis ply.

As expected, after delamination kinks from the original defect plane, it migrates as an intralaminar matrix crack in a surface that is parallel to the fibres. The proposed micromechanical framework is able to predict this behaviour, as shown in Figure 15, where the fracture surfaces originated from the 
$60^{\circ} / 0^{\circ}$ (Figure $15 \mathrm{a}$ ) and $75^{\circ} / 0^{\circ}$ (Figure $15 \mathrm{~b}$ UCs are displayed in different views. Varying the upper al. 12] after delamination migration are positive along the width of the specimen, and negative before migration. In the simulations presented here (Figure 17), only the $0^{\circ} / 0^{\circ}$ and the $15^{\circ} / 0^{\circ} \mathrm{UCs}$ did not present a positive shear stress distribution. The $0^{\circ} / 0^{\circ} \mathrm{UC}$ presents a more uniform and close to zero shear stress distribution, due to symmetry considerations, where the minor fluctuations around a negative stress distribution, causing the crack not to kink and remain at the current interface. All 
the other multidirectional UCs present a positive interlaminar shear stress along their width, which represents the appearance of a shear component at the crack tip causing the crack to migrate as an intralaminar matrix crack towards the next ply interface.

[Figure 17 about here.]

The numerical predictions of the kink angles ranged approximately from $22^{\circ}$ to $62^{\circ}$, increasing as the orientation of the upper ply, $\theta$, increases. The values obtained from experiments [13, 14, are reported for a delamination occurring at a $60^{\circ}$ and $75^{\circ}$ interface. The migration angles obtained numerically for the $60^{\circ} / 0^{\circ}$ and $75^{\circ} / 0^{\circ}$ UCs are comparable to experiments, since the values are approximately $\Omega_{0} \approx 50^{\circ}$ (Figure 18a) and $\Omega_{0} \approx 62^{\circ}$ (Figure 18b), respectively.

[Figure 18 about here.]

\section{4. $90^{\circ} / 90^{\circ} U C$}

The interlaminar crack propagation at a $90^{\circ} / 90^{\circ} \mathrm{UC}$ is simulated here to evaluate the mechanisms behind the delamination migration phenomena at the microscale of a laminate with a symmetric stacking sequence of off-axis plies.

Figure 19 shows the contour plots of the matrix damage variable on the $90^{\circ} / 90^{\circ}$ micromechanical UC. Since this is a symmetric stacking sequence, a pure mode I load is applied at the crack tip, and the interlaminar crack extends along the interface between the $90^{\circ}$ plies (Figure 19a). However, during propagation, due to the proximity of the transversely-oriented fibres on both plies of the UC, throughthickness matrix damage growth through the fibre-matrix interface is promoted, leading to a kink angle $\Omega_{\mathrm{o}} \approx 60^{\circ}$ (Figure 19b). Finally, damage propagates towards the adjacent interfaces (Figure 19c).

[Figure 19 about here.]

Numerical predictions of the interlaminar shear stresses at the crack tip (region 1) and at the point where the crack migrates (region 2) are shown and compared in Figure 20, where the normalisation data point is the same as the one mentioned above, which is at the middle of the width of the UC at the pre-crack tip.

[Figure 20 about here.]

Since this analysis simulates a laminate with a symmetric stacking sequence, due to the heterogeneous nature of the composite, the interlaminar shear stresses oscillate around zero, even for region 2 , and migration occurs due to the proximity of the fibre-matrix interface, leading to the formation of an intralaminar matrix crack. 


\section{Concluding remarks}

In this work, a detailed representation of interlaminar crack propagation and migration between angled plies has been studied using a three-dimensional finite element computational micromechanics framework, composed by a micromechanical UC and homogenised outer plies. Appropriate constitutive models were used to model the different dissipative phenomena that occur at crack propagation. The properties of the homogenised plies have been obtained from different periodic RVEs with random fibre distributions and subjected to PBCs. UCs with different fibre orientations and ply thicknesses were generated to simulate interlaminar damage propagation and relocation. In the present work:

- The influence of ply thickness on the interlaminar damage relocation was analysed, where $75^{\circ} / 0^{\circ}$ UCs were generated with different ply thicknesses. As expected, the crack migrated to the next ply interface through an intralaminar matrix crack. The numerical predictions of the interlaminar shear stress along the width of the UCs were positive, independently of the thickness of the UCs. With increasing ply thickness, the magnitude of the shear stresses decreases, which is apparently the cause of why the values of the kink angles decrease.

- In multidirectional laminates with $\theta / 0^{\circ}$ interfaces, delamination migration occurred for fibre orientations equal to or above $\theta=30^{\circ}$. Since the computational model simulates mode I interlaminar fracture testing, the crack migrated directly from the film insert, as reported in [13], and the intralaminar matrix crack migrated in a surface that is parallel to the ply orientation, as reported in [13, 14]. Through comparison with CT scans captured by Gong et al [13], the models are able to capture the triangular-shaped crack that is formed in the next ply interface where the crack migrates to. It was concluded, as well, that these shapes vary with the reinforcement orientation, $\theta$.

- The occurrence of migration is directly dependent on the sign of the component of the interlaminar shear stress perpendicular to the $\theta$ fibre direction [10, 12], which leads to a shear mode fracture component at the crack tip [13. Numerical predictions of the interlaminar shear stress distributions along the width of the UC were obtained and qualitatively compared with experimental results obained by Pernice et al. [12]. It was concluded that the crack migrates only for the cases where the shear stress distribution is positive, as reported by Pernice et al. [12]. Kink angles, $\Omega_{0}$, ranging from $22^{\circ}$ to $62^{\circ}$, were predicted, increasing with increasing orientation of the upper ply, $\theta$, comparable with previously conducted experimental observations [13, 14.

- A micromechanical simulation of interlaminar damage propagation in a $90^{\circ} / 90^{\circ}$ interface showed that the crack initially propagates in the interlaminar region before migrating through the thickness (with $\Omega_{0} \approx 60^{\circ}$ ). Analysing the interlaminar shear stress distributions, it can be concluded 
that, for a delamination propagating between symmetric sub-laminates, migration may still occur through the weak fibre-matrix interfaces due to the proximity of the randomly distributed fibres.

This study shows that computational micromechanics can be regarded as a reliable tool to analyse different types of phenomena whose contribution is usually neglected in laminate-level analyses. The potential of computational micromechanics can therefore be extended to the analysis and understanding of other loading scenarios, including migration under mode II loading [14] and the effect of stress triaxiality [25], and the search for solutions to prevent this type of phenomena (e.g. optimisation of ply mismatch orientation, application of thin plies, inclusion of additional constituents such as reinforcing particles and nano-reinforcements, etc.).

\section{Acknowledgements}

The authors gratefully acknowledge the financial support of the project ICONIC - Improving the crashworthiness of composite transportation structures. ICONIC has received funding from the European Unions Horizon 2020 research and innovation programme under the Marie Skodowska-Curie grant agreement No 721256. The content reflects only the authors view and the Agency is not responsible for any use that may be made of the information it contains. The second author would like to thank the financial support provided by FCT - Fundação para a Ciência e a Tecnologia through National Funds in the scope of project MITP-TB/PFM/0005/2013.

\section{Data availability}

Datasets related to this article can be found at http://dx.doi.org/10.17632/gwpf5dtv8z.1, an opensource online data repository hosted at Mendeley Data.

\section{References}

[1] T. L. Anderson. Fracture Mechanics: Fundamentals and Applications, volume 58. 2012.

[2] D. J. Nicholls and J. P. Gallagher. Determination of GIC in Angle Ply Composites Using a Cantilever Beam Test Method. Journal of Reinforced Plastics and Composites, 2(1):2-17, 1983.

[3] Emile S. Greenhalgh, Charlotte Rogers, and Paul Robinson. Fractographic observations on delamination growth and the subsequent migration through the laminate. Composites Science and Technology, 69(14):2345-2351, 2009.

[4] Ming-Yuan He and John W. Hutchinson. Kinking of a Crack Out of an Interface. Journal of Applied Mechanics, 56(2):270, 1989. 
[14] Yu Gong, Bing Zhang, Supratik Mukhopadhyay, and Stephen R. Hallett. Experimental study on delamination migration in multidirectional laminates under mode II static and fatigue loading, with comparison to mode I. Composite Structures, 201(June):683-698, 2018.

[15] M. McElroy, F. Leone, J. Ratcliffe, M. Czabaj, and F. G. Yuan. Simulation of delaminationmigration and core crushing in a CFRP sandwich structure. Composites Part A: Applied Science and Manufacturing, 79:192-202, 2015.

[16] X. F. Hu, B. Y. Chen, M. Tirvaudey, V. B. C. Tan, and T. E. Tay. Integrated XFEM-CE analysis of delamination migration in multi-directional composite laminates. Composites Part A: Applied Science and Manufacturing, 90:161-173, 2016. 
[17] N. V. De Carvalho, B. Y. Chen, S. T. Pinho, J. G. Ratcliffe, P. M. Baiz, and T. E. Tay. Modeling delamination migration in cross-ply tape laminates. Composites Part A, 71:192-203, 2015.

[18] Mark McElroy. Use of an enriched shell finite element to simulate delamination-migration in a composite laminate. Composite Structures, 167:88-95, 2017.

[19] X. Li and J. Chen. A highly efficient prediction of delamination migration in laminated composites using the extended cohesive damage model. Composite Structures, 160:712-721, 2017.

[20] B. Y. Chen, T. E. Tay, S. T. Pinho, and V. B. C. Tan. Modelling delamination migration in angle-ply laminates. Composites Science and Technology, 142:145-155, 2017.

[21] A. R. Melro, P. P. Camanho, F. M. Andrade Pires, and S. T. Pinho. Micromechanical analysis of polymer composites reinforced by unidirectional fibres: Part II-Micromechanical analyses. International Journal of Solids and Structures, 50(11-12):1906-1915, 2013.

[22] Ganesh Soni, Ramesh Singh, Mira Mitra, and Brian G. Falzon. Modelling matrix damage and fibre-matrix interfacial decohesion in composite laminates via a multi-fibre multi-layer representative volume element (M2RVE). International Journal of Solids and Structures, 51(2):449-461, 2014.

[23] A. Arteiro, G. Catalanotti, A. R. Melro, P. Linde, and P. P. Camanho. Micro-mechanical analysis of the in situ effect in polymer composite laminates. Composite Structures, 116(1):827-840, 2014.

[24] A. Arteiro, G. Catalanotti, A. R. Melro, P. Linde, and P. P. Camanho. Micro-mechanical analysis of the effect of ply thickness on the transverse compressive strength of polymer composites. Composites Part A: Applied Science and Manufacturing, 79:127-137, 2015.

[25] L. F. Varandas, A. Arteiro, M. A. Bessa, A. R. Melro, and G. Catalanotti. The effect of throughthickness compressive stress on mode II interlaminar crack propagation: A computational micromechanics approach. Composite Structures, 2017.

[26] F. Naya, C. González, C. S. Lopes, S. Van der Veen, and F. Pons. Computational micromechanics of the transverse and shear behavior of unidirectional fiber reinforced polymers including environmental effects. Composites Part A: Applied Science and Manufacturing, 92(June):146-157, 2017.

[27] F. Naya, M. Herráez, C. S. Lopes, C. González, S. Van der Veen, and F. Pons. Computational micromechanics of fiber kinking in unidirectional FRP under different environmental conditions. Composites Science and Technology, 144:26-35, 2017.

[28] Vít Šmilauer, Christian G. Hoover, Zdeněk P. Bažant, Ferhun C. Caner, Anthony M. Waas, and Khaled W. Shahwan. Multiscale simulation of fracture of braided composites via repetitive unit cells. Engineering Fracture Mechanics, 78(6):901-918, 2011.

[29] Tadayoshi Yamanaka, Hossein Ghiasi, Mohammad Heidari-Rarani, Larry Lessard, Victor Feret, 
and Pascal Hubert. Multiscale finite element analysis of mode I delamination growth in a fabric composite. Composite Structures, 133:157-165, 2015.

[30] A. R. Melro, P. P. Camanho, F. M. Andrade Pires, and S. T. Pinho. Micromechanical analysis of polymer composites reinforced by unidirectional fibres: Part I-Constitutive modelling. International Journal of Solids and Structures, 50(11-12):1897-1905, 2013.

[31] N. W. Tschoegl. Failure surfaces in principal stress space. Journal of polymer science Part C: Polymer symposia, 32(1):239-267, 1971.

[32] Z. Bažant and B. Oh. Crack band theory of concrete. Materials and Structures, 16:155-177, 1983.

[33] Dassault Systèmes, Providence, RI, USA. ABAQUS Documentation.

[34] Lin Ye. Role of matrix resin in delamination onset and growth in composite laminates. Composites Science and Technology, 33(4):257-277, 1988.

[35] M. L. Benzeggagh and M. Kenane. Measurement of mixed-mode delamination fracture toughness of unidirectional glass/epoxy composites with mixed-mode bending apparatus. Composites Science and Technology, 56(4):439-449, 1996.

[36] J. Varna, L. A. Berglund, and M. L. Ericson. Transverse single-fibre test for interfacial debonding in composites: 2. Modelling. Composites Part A: Applied Science and Manufacturing, 28(4):317$326,1997$.

[37] F. Naya, J. M. Molina-Aldareguía, C. S. Lopes, C. González, and J. Llorca. Interface Characterization in Fiber-Reinforced Polymer-Matrix Composites. JOM, 69(1):13-21, 2017.

[38] W. Tan, F. Naya, L. Yang, T. Chang, B. G. Falzon, L. Zhan, J. M. Molina-Aldareguía, C. González, and J. Llorca. The role of interfacial properties on the intralaminar and interlaminar damage behaviour of unidirectional composite laminates: Experimental characterization and multiscale modelling. Composites Part B: Engineering, 138(December 2017):206-221, 2018.

[39] T. J. Vaughan and C. T. McCarthy. Micromechanical modelling of the transverse damage behaviour in fibre reinforced composites. Composites Science and Technology, 71(3):388-396, 2011.

[40] Linqi Zhuang, Ramesh Talreja, and Janis Varna. Transverse crack formation in unidirectional composites by linking of fibre/matrix debond cracks. Composites Part A: Applied Science and Manufacturing, 107(February):294-303, 2018.

[41] G. Catalanotti. On the generation of RVE-based models of composites reinforced with long fibres or spherical particles. Composite Structures, 138:84-95, 2016.

[42] A. R. Melro, P. P. Camanho, and S. T. Pinho. Influence of geometrical parameters on the elastic response of unidirectional composite materials. Composite Structures, 94(11):3223-3231, 2012.

[43] P. P. Camanho, P. Maimí, and C. G. Dávila. Prediction of size effects in notched laminates using continuum damage mechanics. Composites Science and Technology, 67(13):2715-2727, 2007. 
[44] ASTM D5528-13, Standard Test Method for Mode I Interlaminar Fracture Toughness of Unidirectional Fiber-Reinforced Polymer Matrix Composites, 2013.

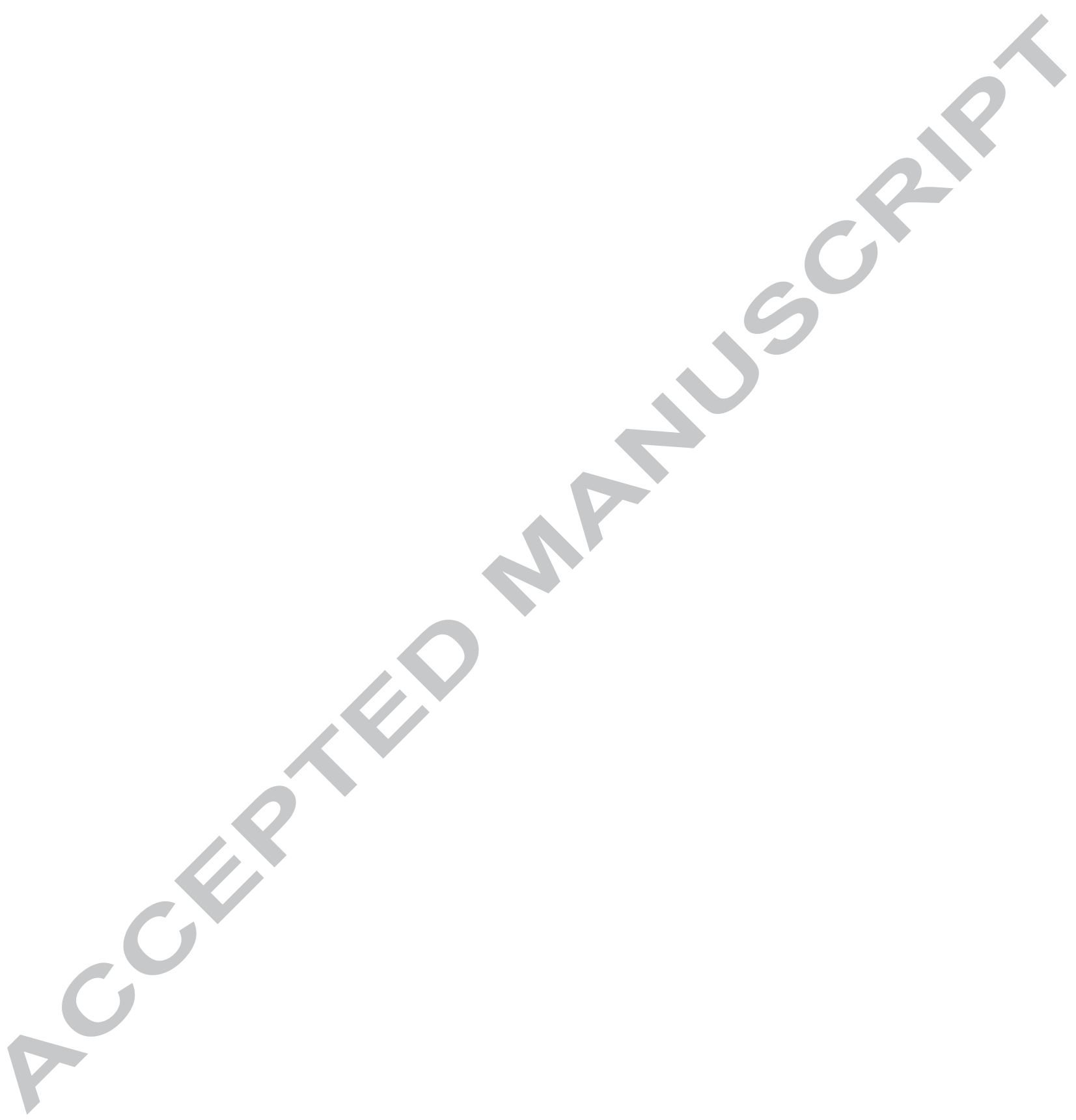


Figure 1: Delamination migration.

Figure 2: Double-ply $\theta / 0^{\circ}$ oriented UC of a laminate, and homogenised outer plies.

575

580

585

590

(a) Double-ply UC, with the top homogenised outer plies.

(b) Entire model (dimensions are not to scale).

Figure 3: Model schematic views. 
(a) Tensile hardening curve.

(b) Compression hardening curve.

Figure 4: Hardening curves used in the plasticity model of the epoxy matrix [23, 24].

Figure 5: Example of generated RVE using [41].

Figure 6: Schematic representation of the setup of the delamination migration experiments by Ratcliffe et al [10, 11].
(a) $h=35 \mu \mathrm{m}$.
(b) $h=65 \mu \mathrm{m}$.
(c) $h=95 \mu \mathrm{m}$.
(d) $h=125 \mu \mathrm{m}$.

Figure 7: Contour plots of the matrix damage variable for the $75^{\circ} / 0^{\circ}$ UCs at maximum applied displacement (only part of the micromechanical UC is shown).

Figure 8: a) UC front view; b) fibres top view highlighting the principal shear stress at the crack tip.

Figure 9: Numerical predictions of the interlaminar shear stress distributions along the width for all the $75^{\circ} / 0^{\circ} \mathrm{UCs}$ at onset of crack propagation.
(a) $h=35 \mu \mathrm{m}$.
(b) $h=125 \mu \mathrm{m}$.

Figure 10: Directions of the maximum principal stress of the elements at the crack tip. (For interpretation of the references to colours in this figure, the reader is referred to the web version of this article.)

(a) Contour plots of the matrix damage variable (only part of the micromechanical UC is shown).

(b) Quantitative comparison of the magnitude of interlaminar shear stresses.

Figure 11: Numerical predictions of the UC with $h=35 \mu \mathrm{m}$ and different homogenised ply thicknesses: $t=35 \mu \mathrm{m}$ and $t=125 \mu \mathrm{m}$.
(a) $0^{\circ} / 0^{\circ} \mathrm{UC}$.
(b) $45^{\circ} / 0^{\circ} \mathrm{UC}$.
(c) $90^{\circ} / 0^{\circ} \mathrm{UC}$.

Figure 12: Contour plots of the matrix damage variable at the maximum applied displacement (only part of the micromechanical UC is shown). 

(a) $15^{\circ} / 0^{\circ} \mathrm{UC}$.
(b) $30^{\circ} / 0^{\circ} \mathrm{UC}$.
(c) $60^{\circ} / 0^{\circ} \mathrm{UC}$.
(d) $75^{\circ} / 0^{\circ} \mathrm{UC}$.

Figure 13: Contour plots of the matrix damage variable at the maximum applied displacement for multidirectional UCs with different off-axis plies (only part of the micromechanical UC is shown).

Figure 14: Numerical predictions of the normalised force vs. normalised displacement curves obtained for different fibre orientations, $\theta$.
(a) $60^{\circ} / 0^{\circ} \mathrm{UC}$.
(b) $75^{\circ} / 0^{\circ} \mathrm{UC}$.

Figure 15: Fracture surfaces displayed in a front view (left) and in an isometric view (right) at maximum applied displacement. (For interpretation of the references to colours in this figure, the reader is referred to the web version of this article.)
(a) $60^{\circ} / 0^{\circ} \mathrm{UC}$
(b) $75^{\circ} / 0^{\circ} \mathrm{UC}$

Figure 16: 1) Contour plots of the matrix damage variable at the $0^{\circ} / \theta$ interface. 2) and 3) CT scans of a lower $-\theta /+\theta$ delamination of a quasi-static test obtained by Gong et al. [13] (with permission). (For interpretation of the references to colours in this figure, the reader is referred to the web version of this article.)

Figure 17: Numerical predictions of the interlaminar shear stress perpendicular to the fibre orientation of the upper ply (see Figure 8 along the width of the UC for different fibre orientations, $\theta$.
(a) $60^{\circ} / 0^{\circ} \mathrm{UC}$.
(b) $75^{\circ} / 0^{\circ} \mathrm{UC}$

Figure 18: Numerical predictions of the kink angle, $\Omega_{0}$ (only part of the micromechanical UC is shown).

(a) Interlaminar damage propagation.

(b) Fibre-matrix interface damage.

(c) Plies interface damage.

Figure 19: Contour plots of the matrix damage variable for the $90^{\circ} / 90^{\circ} \mathrm{UC}$ (only part of the micromechanical UC is shown).

Figure 20: Numerical predictions of the interlaminar shear stresses at the crack tip and at the point where the crack migrates to the next interlaminar regions. 
Table 1: Fibre material properties

\begin{tabular}{ll}
\hline Material property & Value \\
\hline $\begin{array}{l}\text { Fibre diameter } \\
2 r[\mathrm{~mm}]\end{array}$ & 0.007 \\
Young's moduli & \\
$E_{11}[\mathrm{MPa}]$ & 276000 \\
$E_{22}[\mathrm{MPa}]$ & 15000 \\
Poisson's ratio & \\
$\nu_{12}$ & 0.2 \\
Shear moduli & \\
$G_{12}[\mathrm{MPa}]$ & 15000 \\
$G_{23}[\mathrm{MPa}]$ & 7000 \\
Density $\left[\right.$ tonne/mm $\left.{ }^{3}\right]$ & $1.78 \times 10^{-9}$ \\
\hline
\end{tabular}

Table 2: Matrix material properties 23, 24].

\begin{tabular}{ll}
\hline Material property & Value \\
\hline Young's modulus & \\
$E_{m}[\mathrm{MPa}]$ & 3760
\end{tabular}

Poisson's ratio

Plastic Poisson's ratio

$\nu_{p}$

Tensile strength

$X_{m}^{t}[\mathrm{MPa}]$

Compressive strength $X_{m}^{c}[\mathrm{MPa}]$ 350

Mode I fracture toughness $\mathcal{G}_{I c}^{m}[\mathrm{~N} / \mathrm{mm}]$

Density

$\rho\left[\right.$ tonne $\left./ \mathrm{mm}^{3}\right]$ $1.3 \times 10^{-9}$ 
Table 3: Fibre-matrix interface properties [21, 23, 24].

\begin{tabular}{lc}
\hline Material property & Value \\
\hline Interface stiffness & \\
$K\left[\mathrm{~N} / \mathrm{mm}^{3}\right]$ & $10^{8}$ \\
Interface maximum strengths & 75 \\
$\tau_{1}^{0}[\mathrm{MPa}]$ & 75 \\
$\tau_{2}^{0}[\mathrm{MPa}]$ & 50 \\
$\tau_{3}^{0}[\mathrm{MPa}]$ & \\
Interface critical energy release rates & 0.002 \\
$\mathcal{G}_{I c}[\mathrm{~N} / \mathrm{mm}]$ & 0.006 \\
$\mathcal{G}_{I I c}[\mathrm{~N} / \mathrm{mm}]$ & 0.006 \\
$\mathcal{G}_{I I I c}[\mathrm{~N} / \mathrm{mm}]$ & \\
Mixed-mode interaction parameter $(\mathrm{BK}$ law $[35])$ & 1.45 \\
$\eta$ &
\end{tabular}

Table 4: Homogenised plies properties.

\begin{tabular}{llll}
\hline Material property & Mean & Minimum & Maximum \\
\hline Young's moduli & & & \\
$E_{11}[\mathrm{MPa}]$ & 168000 & 167762 & 168251 \\
$E_{22}[\mathrm{MPa}]$ & 9300 & 9212 & 9311 \\
Poisson's ratio & & & \\
$\nu_{12}$ & 0.262 & 0.257 & 0.268 \\
$\begin{array}{l}\text { Shear moduli } \\
G_{12}[\mathrm{MPa}]\end{array}$ & 5300 & 5185 & 5403 \\
$G_{23}[\mathrm{MPa}]$ & 3500 & 3441 & 3662 \\
$\begin{array}{l}\text { Density } \\
\left.\rho \text { [tonne } / \mathrm{mm}^{3}\right]\end{array}$ & $1.58 \times 10^{-9}$ & ---- & $--\cdot-$ \\
\hline
\end{tabular}


Table 5: Interlaminar properties of the carbon-epoxy composite laminate 43.

\begin{tabular}{lc}
\hline Material property & Value \\
\hline Interface stiffness & \\
$K\left[\mathrm{~N} / \mathrm{mm}^{3}\right]$ & $10^{8}$
\end{tabular}

Interface maximum strengths

$\tau_{1}^{0}[\mathrm{MPa}]$

$\tau_{2}^{0}[\mathrm{MPa}]$

10

$\tau_{3}^{0}[\mathrm{MPa}]$

Interface critical energy release rates

$\mathcal{G}_{I c}[\mathrm{~N} / \mathrm{mm}]$

$\mathcal{G}_{I I c}[\mathrm{~N} / \mathrm{mm}]$

0.788

$\mathcal{G}_{\text {IIIC }}[\mathrm{N} / \mathrm{mm}]$

0.788

Mixed-mode interaction parameter (BK law 35]) 